\title{
Innovation for sustainable development: from environmental design to transition management
}

\author{
Karel F. Mulder
}

Received: 3 April 2007 / Accepted: 29 June 2007/Published online: 1 September 2007

(C) Integrated Research System for Sustainability Science and Springer 2007

\begin{abstract}
Society needs to adapt in order to provide the wealth that an increasing part of the world population is getting used to. We are on a track to ecological and resource collapse if actions are not taken soon. Technology will have to play a key role in the process of changing industrial society. But innovation has to be embedded in social and organizational innovation. We need sociotechnical change. Environmentally conscious design has been practiced in engineering design for more than a decade. Its merits are sometimes blamed as futile, as the world has not witnessed a significant contribution to the solution of the larger (global) problems. This paper first sketches a scheme of the various levels of technological change, ranging from: (1) incremental optimizations of single artifacts, to (2) major change of artifacts, (3) systems change, and (4) technological transitions (involving changes in production and consumption). It outlines the stakeholders involved in these types of innovations and the parties that could orchestrate the innovation process. In this paper, It is argued that the most encompassing level of technological innovation, the level of transition, is crucial for achieving long-term sustainable development, as it has the largest potential for improvement. However, transition is not very well manageable. The paper contains a review of the literature regarding the occurrence of technological transitions. After a transition has occurred, the new system is often not efficient. Its gains in terms of diminished resource consumption or pollution have to be enlarged by
\end{abstract}

\footnotetext{
K. F. Mulder ( $\square)$

Faculty of Technology, Policy and Management, Department of Technology Dynamics and Sustainable

Development, Delft University of Technology,

Jaffalaan 5, 2628 RZ Delft, The Netherlands

e-mail: k.f.mulder@tbm.tudelft.nl
}

less encompassing innovation strategies, such as systems innovations and product optimization. Transitions for sustainable development are often impossible, as the new systems have to compete with fully developed and optimized systems that have far advanced at the learning curve, i.e., are optimized by various systems and incremental innovations. Less encompassing levels of innovation, even those that aim at more sustainability, can counteract transitions that have more potential for sustainable development by improving the competing (unsustainable) technology. The paper will give several examples of this dilemma and some guidelines for developing government policies as well as corporate strategies. On the policy level, it is argued that it is especially important to develop (scope for) market niches for new sustainable systems and products as they create scope for experiments that could lead to transitions.

Keywords Innovation · Technology · Backcasting · Scenario · Plastics

\section{Introduction}

The need for more sustainable products and modes of production

Technological innovation is a "must" for sustainable development. It is not a nerdish focus on technology, but an attempt to create options. Since the early 1990s, industrial ecology was introduced as an approach that aimed at improving the environmental efficiency of technological systems (Graedel and Allenby 1995). However, the focus of this approach was often on optimization. It is the aim of this paper to introduce a framework for longer-term 
sustainability-focused technology policy. Ehrlich and Holdren (1972) introduced a simplified equation:

$I=P \times A \times T$

$I$ environmental impact

$P$ population

$A$ affluence (consumption of services and products per capita)

$T$ technology, (environmental burden per product or service unit)

As the global population is expected to grow from 6 billion to at least 9 billion by 2050, and the affluence of developing nations will (have to) rise considerably, the environmental efficiency of technology, $T$, should be improved by a factor 4-40 simply to keep the environmental burden the same as it is today (Weterings and Opschoor 1992).

\section{Technologies for sustainable development}

Having recognized the need for innovation for sustainable development, it is not evident what should be done. There are several options that contribute to diminish the environmental burden of human activities. New technologies always entail social change. The successful introduction of a new technology is therefore always a matter of sociotechnical change. In the following sections, a range of sociotechnical solutions for environmental problems is discussed. These technologies have been categorized according to their degree of "radicalism," i.e., the degree to which they affect current technological systems:
1. Preindustrial solutions

2. Classic environmental technologies

3. Good housekeeping technologies

4. End-of-pipe technologies

5. Process adaptation and damage prevention

6. Sustainable technologies

It should be noted that technologies to protect human society from the hazards of nature, such as surge barriers and vaccination, are not termed environmental technologies. Likewise excluded are technologies used for measurement and analysis. Although of great importance, these technologies are not generally specific to environmental problems.

Restoration technologies (for soil remediation and so on) are included in the definition, however, as are so-called endof-pipe technologies, and it is to this kind of environmental technology that is now examined, thereby following the categories of Table 1.

1. Man has always used technologies. Their use sometimes led to local overexploitation of natural resources and local pollution. These problems were often limited by negative feed back (local exhaustion) and by very low densities of human population.

2. Historically, the first environmental problems were of a local nature. The easiest way to tackle these problems was by using classic, so-called triple $D$ technologies:

- Dumping (of waste in pits, etc.)

- Displacement (of pollution by sewerage, smoke stacks, etc.)

- Dilution (of gaseous and liquid waste)

In this category of environmental technologies, the pollution is not chemically or biologically transformed.

Table 1 Environmental classification of technologies

\begin{tabular}{|c|c|c|c|c|c|}
\hline Technology type & Function & $\begin{array}{l}\text { Resources } \\
\text { predominantly used }\end{array}$ & $\begin{array}{l}\text { Resource } \\
\text { efficiency }\end{array}$ & Emissions & Impact on natural systems \\
\hline 1. Preindustrial technologies & To provide & Renewable & Low to high & Low & $\begin{array}{l}\text { Some overexploitation, } \\
\text { often compensated by } \\
\text { low density of population }\end{array}$ \\
\hline $\begin{array}{l}\text { 2. Classic environmental } \\
\text { technologies }\end{array}$ & $\begin{array}{l}\text { To prevent harm by } \\
\text { pollution }\end{array}$ & Nonrenewable & Low & High & $\begin{array}{l}\text { Ecological destruction outside } \\
\text { settlements }\end{array}$ \\
\hline $\begin{array}{l}\text { 3. Good housekeeping } \\
\text { technologies }\end{array}$ & To mitigate pollution & Nonrenewable & $\begin{array}{l}\text { Medium to } \\
\text { low }\end{array}$ & $\begin{array}{l}\text { Medium to } \\
\text { low }\end{array}$ & $\begin{array}{l}\text { Mitigation of ecological } \\
\text { destruction }\end{array}$ \\
\hline $\begin{array}{l}\text { 4. End-of-pipe } \\
\text { technologies }\end{array}$ & $\begin{array}{l}\text { To prevent pollution } \\
\text { after process }\end{array}$ & Nonrenewable & $\begin{array}{l}\text { Medium to } \\
\text { low }\end{array}$ & Low & $\begin{array}{l}\text { Less pollution, at the expense } \\
\text { of extra resource use }\end{array}$ \\
\hline $\begin{array}{l}\text { 5. Process } \\
\text { adaptation/damage } \\
\text { prevention }\end{array}$ & $\begin{array}{l}\text { To prevent pollution } \\
\text { arising in process }\end{array}$ & $\begin{array}{l}\text { Nonrenewable } \\
\text { and renewable }\end{array}$ & High & Low & $\begin{array}{l}\text { Less pollution and less } \\
\text { resource use }\end{array}$ \\
\hline $\begin{array}{l}\text { 6. Sustainable } \\
\text { technologies }\end{array}$ & $\begin{array}{l}\text { To provide within the } \\
\text { limits of the earth's } \\
\text { carrying capacity }\end{array}$ & Renewable & High & None & $\begin{array}{l}\text { Balance between humanity } \\
\text { and the natural environment }\end{array}$ \\
\hline
\end{tabular}


3. As pollution became problematical, people began to think about pollution prevention. The first initiatives in this direction are always the easiest: options to minimize pollution are sought within the constraints of existing modes of production. This generally comes down to basic precautionary measures, or what is nowadays called good housekeeping, or triple $M$ :

- Monitoring

- Management

- Maintenance

4. Reduction of the remaining waste can be achieved by means of end-of-pipe technologies, including, in particular:

- Incineration

- Pyrolysis

- Separation

- Fermentation

- Chemical transformation

- Catalytic reduction

- Shielding (radiation, noise)

Recycling and re-use technologies that feed waste (product) back into production processes can be termed end-of-pipe if the waste in question is from a different process loop, as in the case of waste being used as a fuel, for example. If waste is re-used in the same production loop without requiring much additional energy or generating much pollution, however, recycling may be sustainable (as in the case of reprocessed metals).

End-of-pipe technologies are often denounced as providing no real solution to the problem of pollution. In many cases, these technologies create new problems, as the pollution prevented from being emitted must be stored, treated, or discharged in some other way. For the short-term future, they cannot be done without; however, as the introduction of alternatives will often require tremendous efforts.

Restoration technology is a specific kind of end-of-pipe technology. There is an obligation, at the very least, to clear up the worst pollution of the past and insulate polluted sites from their unpolluted environment. Areas where restoration is required include the following:

- Polluted soils

- Polluted lake and river bottoms

- Space debris

- Plastic wastes in the oceans

- Nuclear waste

- Nonindigenous species introduced into ecosystems

5. In many cases, however, the preferred option is to reduce the environmental burden by creating a clean production process. In this way, further reduction of pollution and resource consumption can be achieved. Complete redesign of production processes can lead to both environmental gains and cost reduction. Various tools are available for this purpose:

- Industrial ecology: integral design of industrial systems to minimize resource consumption and waste production by intelligent combinations of facilities.

- Life-cycle assessment: analyzing the overall production chain and identifying the main target areas for environmental and resource improvement.

- Pinch technology: minimizing resource consumption in production processes by minimizing process redundancies.

6. Ultimately, technologies must be developed for sustainable production and consumption, for none of the above technologies will suffice to solve the environmental problems being faced. Sustainable technologies go beyond environmental technologies. Whereas the latter are concerned with producing goods and services with minimal pollution, sustainable technologies have a far broader aim: to enable the needs of the whole of humanity to be fulfilled without:

- Exhausting the earth's nonrenewable resources

- Exceeding its ecological recovery capacity

- Consolidating or promoting inequity

These technologies must enable humanity to survive in the longer term, that is to say, sustainable technologies are a necessary condition for the continuity of human civilization.

\section{Innovation}

How to reach those technologies? What type of innovation process might lead to sustainable technologies? In a well known paper, Abernathy and Clarke (1985) introduced a taxonomy of technological innovation (Fig. 1). They distinguished:

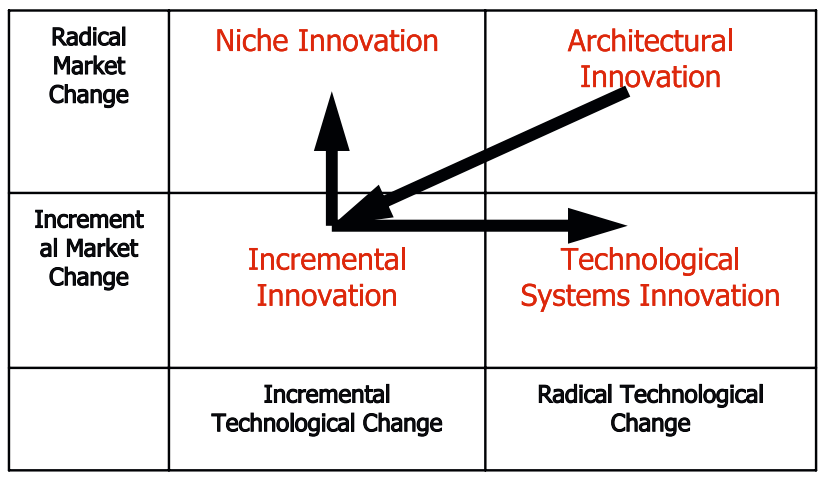

Fig. 1 Types of innovation (Abernathy and Clark 1985) 
- Architectural

- Niche

- Incremental

- Technological systems innovations

Architectural innovations are rare. The success rate of attempts to innovate in an architectural way is often very low. Cell phones are one of the few successful architectural innovations that happened rather recently. Architectural innovations have great impact. They do not merely optimize an existing function, but the technology creates completely new options for behavior. As this has occurred, there are many options for improvement: incremental innovation can rapidly cut the costs and/or increase the performance of the technology. This creates a rapid growth in the industry as it facilitates further market penetration. As incremental innovation gradually meets limits, growth can be sustained by other options: market niches create a possibility to create extra demand and premium prices. Moreover, as the regular incremental innovation becomes harder, technologists might start working on more radical, risky improvements to the technological system (such as switching to other frequencies for cell phones that could limit the number of ground stations). All these types of innovation might contribute to sustainable development. Architectural innovations are rather unpredictable in this respect, as it they generally also change the behavior and needs of consumers. From historic analyses of technological innovations, one might draw some conclusions on what could be achieved:

- Optimal use of existing technology: By diffusion of best practices, no spills, good maintenance of installations, the environmental burden might be reduced by 550\%. End-of-pipe technologies prevent emissions. However, these technologies require energy and often do not destroy the pollutant but change its state. Endof-pipe technologies might bring considerable local environmental gains but often at the expense of extra resource consumption (especially energy consumption)Technology systems renewal might create real environmental gains. Emissions might be prevented; energy use might be optimized (Cf., e.g., cogeneration of heat and power). These innovations require large investments and are always destructive for (parts of) the system that they supersede. The telegraph system was almost destroyed by the telex. Later, both technologies were swept away by the introduction of the fax. As a consequence of this destructive nature of systems innovations, actors connected to existing production systems are often opposed to the introduction of new systems. People might point toward the risks involved, and the "cannibalizing" effect of the innovations.
However, as Sony founder Akio Morita once said, "a company is better off cannibalizing its own technologies than having somebody else do it for them" (Rheingold 1986).

- Niche innovations might further improve the environmental performance of technologies (as the match between technology and demand can be improved) but might also involve new features and additional consumption. Their effect is limited.

These technological improvements will probably not be sufficient, e.g., even if power plants would be able to use almost the complete energy content of fossil fuels, it might still be argued that $\mathrm{CO}_{2}$ production and mineral fuel consumption remain too high. Therefore, also necessary are technological changes that transcend current products: Technologies are required that fulfill the human needs in a far more efficient way. Architectural innovations and technological systems renewal are needed that will enable leaps in resource efficiency and environmental performance.

Architectural innovations greatly affect the existing technological capabilities of firms, but also their existing market relations. Taken even wider, Rotmans introduced the concept of transition, which also involves a whole range of changes in institutions and societal infrastructure (Rotmans et al. 2001). The impact of transitions in terms of sustainability is probably larger than any of the previous technological changes. One might assume that it is especially this type of innovation that could meet resistance from the social structure, culture, and interests related to the current technology.

Technological innovation as a concept is not unproblematic by itself: it might refer to the knowledge of such different entities as large systems, such as the railroad system, or as small as the molecular structure of the surface of the thread of a light bulb. It might also refer to knowledge of activities as different as welding, designing, planning, drawing, leaching, etc. Hence, technology refers to knowledge of different levels of integration of objects in order to perform useful functions for humankind. Technology refers to three realms:

Knowledge, i.e., the cognitive realm, which is emphasized in technological change concepts such as technological regimes (van de Poel 2003; Moors and Mulder 2002).

Integration of objects in a technological system, i.e., the physical realm, which is emphasized in Tom Hughes's (1983) technological systems concept.

Functions, i.e., a technology might fulfill several functions, which are valued differently by stakeholders. This social realm is emphasized in social constructivist concepts of technological change (Bijker et al. 1987). 
As has often been done, one might doubt the ability to affect the course of technological change. Technological determinists have argued that technological change is an autonomous process. Although this vision has few adherents, the barriers to steer the process of technological change (toward sustainability) are considerable. Industrial technology is nowadays geared toward a globalized market, which exerts the same pressure on the industrial corporation. Moreover, barriers to external attempts to steer technological change emerge from:

- The embeddedness of technologies in social practices of consumers, workers, managers.

- The embeddedness of (sub) technologies within complex sociotechnological systems that only allow for incremental changes within individual elements or require great effort for change.

- The embeddedness of a technology within a technological regime, i.e., a dominant concept of defining a technology and the way in which it might be improved by technological innovation.

The importance of these barriers to change differs for various branches of industry. Capital-intensive industry such as, e.g., the basic metals industry, is tightly bound by its existing physical infrastructure and the planned maintenance and replacement schemes. Technological change is only possible at specific intervals, e.g., if parts of this physical infrastructure have to be replaced (Cf. Moors 2000).

The importance of the scientific/technological knowledge base depends on the pace of technological change in industry. Innovative branches of industry often have considerable research and development (R\&D) facilities. However, an industry with a strong knowledge base might also have created a new barrier to change, as R\&D laboratories might have developed their own technological regime that resists radical technological changes.

\section{Innovation for sustainable development}

Not all technological systems renewal, architectural innovations, or transitions necessarily will lead to sustainable development. To begin with, a sustainable technology means more than merely producing goods without pollution or ecological destruction. Sustainable technology means fulfilling people's needs in such a way that the recovery capacity of the planet as well as the recovery capacity of local ecosystems are not exceeded. The aim is to bring the worlds' use of natural resources within the boundaries that are set by the earth's recovery capacity. What are the preconditions that the need for sustainable development sets for these innovations.

\section{Fulfillment of needs}

The first step for developing technologies for sustainable development should be to analyze the need that is fulfilled by the product. One should recognize that consumers might have "hidden" (not articulated) needs. Companies or governments might also have hidden needs, like the prestige of an official or national prestige.

Specific products often raise an issue of legitimacy (should Formula 1 races be allowed; should cigarettes be permitted, etc.). However, these products reflect a need (for a thrill, for comfort) that is, as such, legitimate. The challenge is to develop more sustainable alternatives to fulfill these needs.

Can a need be fulfilled in a different way? If so, is this alternative preferable in environmental, social, and ethical terms?

Thinking in fulfillment of needs often requires crossing disciplinary boundaries. The best solution for a problem might be outside the discipline in which you are trained. Disciplinary training might sometimes prevent you from reaching a leap. It limits the scope of alternatives that to consider. For example:

To melt a metal will always require a minimum amount of energy, no matter how efficiently a process is designed. If further improvements are sought, efficient recycling schemes contribute to reduce the demand for ores and energy consumption. For some applications of a metal like zinc, recycling is impossible, as much zinc is dissipated in use. In the case of galvanized steel, for example, the zinc layer dissipates into the environment. Further progress by means of technological innovation would therefore seem to be impossible... until it is realized that the user does not necessarily want a galvanized steel product! What a user wants is a durable product that renders a specific service.

Brainstorm sessions to generate alternative modes of need fulfillment are very important to open minds for alternative ideas. If brainstorming is carried out vigorously, then in general, many alternatives show up, originating from entirely different sectors. Alternatives for galvanized metals, for example, might include (treated) wood, painted metals (noncorroding metals), plastics, or even a completely redesigned product that renders all these options superfluous. It may even be the case that manufacture of the product can be superseded by providing a service, replacing a transport vehicle by a means for communication, for example. Such radical innovations involve a new production system as well as new marketing channels and new forms of consumption. But the precondition for arriving at these alternatives is to focus on fulfilling a need, not on improving an existing technology. 
Thinking globally

Fulfilling needs in a far more efficient way does not necessarily lead to sustainable solutions. Technologies that are very environmentally efficient might have various negative side effects or have longer-term effects or might only be applicable on small a scale.

- Monsanto's Round Up technology (key elements are an herbicide and a genetically modified corn that is resistant to that herbicide, they are sold in combination) enables farmers to have a higher yield with lower use of herbicides and at lower costs. However, will the genetically modified corn affect ecosystems? Farmers will have to buy the seeds from Monsanto each year. How does this affect the power of farmers vis-à-vis agricultural industry?

- Food aid for regions with high malnutrition rates might keep food prices down. This can be important to stop starvation but will in the long run contribute to the degradation of local agriculture.

- Highly efficient technologies might be too dependent on a resource that could be scarce in the future. For example, various precious metals and rare earth metals that are used to catalyze the breaking down of toxics could become scarce just by a relative small extra demand on the market.

- Antibiotics, for example, are very important in health care, but their wide-scale use creates bacteria that are immune to antibiotics. In the long run, this might create an enormous health risk

Therefore, innovation for sustainable development demands a wide view on innovation. Acting locally is necessary, but so is evaluating technologies globally and with a long-term view. Moreover, technology assessment is crucial also for technologies that are aimed at contributing to the common good.

\section{Looking for long-term solutions}

Small improvements in environmental efficiency are nice but are not enough. The aim must be at making leaps. A dilemma often occurs: Improvement might be made in unsustainable technologies; however, this will not lead to the ultimate (no depletion, clean, safe, etc.) sustainable technology. Should precious R\&D capacity be spent on the small improvement options that can be developed quickly, or should $R \& D$ be dedicated to creating real leaps (that might take considerable time)? In practice the dilemma might take the form of:
- Should developing optimized coal-fired power plants be the goal, or should investments in improving wind turbines be preferred?

- Should large, efficient, and clean municipal solid waste incinerators be developed, or should waste be reduced by prevention and recycling?

- Should more durable houses be developed (that are inflexible, need more materials, but consume less energy), or should the aim be less durable houses (that are more flexible, need fewer materials, but consume more energy)?

The answers are not easy to be given. The improvement of existing technologies is often less risky than aiming at breakthrough technology. Comparisons could be made of various environmental, social, and economic aspects of an investment in an improved coal-fired power plant with the effects of developing an off-shore wind park for the average life span of these technologies. But what about the lasting effects of the creation of new knowledge, new technologies, and the learning that takes place? Learning always occurs from developing a completely new technology (even that the idea does not work in reality), but what is the value of this learning?

The dilemma between short-term improvements vs. long-term sustainable technologies can only be solved by an assessment of all relevant aspects in a long-term perspective. Decisions cannot be made by calculation alone, as it always involves a choice for the kind of society we want to create for the future. And recognizing the dilemma is crucial in order to be able to make conscious decisions. (Fig. 2).

The challenge for sustainable innovation is summarized in Fig. 3: A wider perspective in time should be sought, but also in regard to the stakeholders to be taken into account. The first environmental improvements generally focused

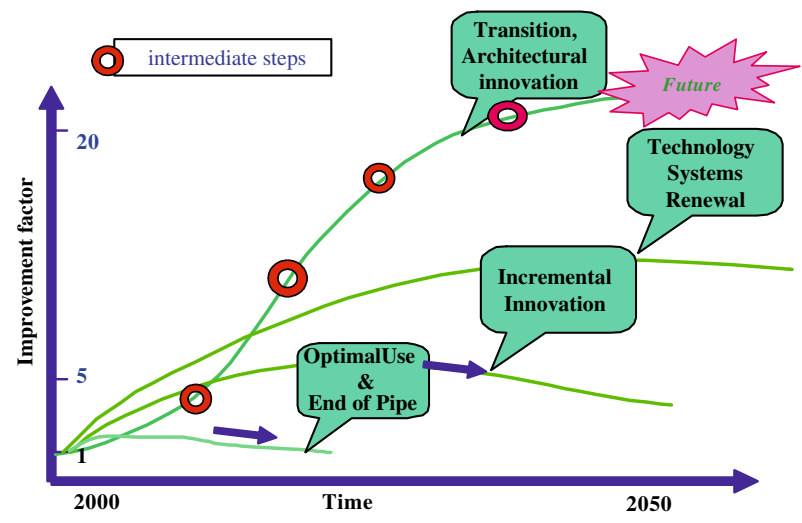

Fig. 2 Improvement strategies for technologies 
Fig. 3 The challenge for sustainable innovation
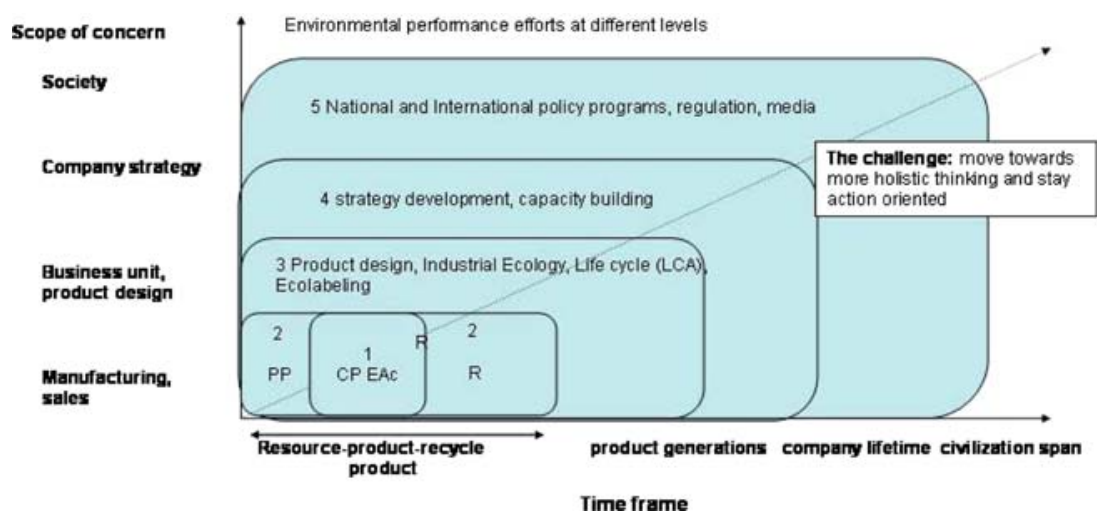

on manufacturing. Methods such as cleaner production (CP) and environmental accounting (EAc) (1) should be complemented by pollution prevention and recycling (2); however, these methods should be complemented with environmentally optimized product design, and industrial ecology (3), which should be embedded in corporate strategy and national policies (4) and take a long-term perspective (5) (Fig. 4).

As end-of-pipe technologies have little or no overall impact on the industrial production system as such, it is generally the preferred solution of industry when it comes to tackling the environmental crisis. However, adapting the overall production system may often represent a far more effective solution, as it might prevent the creation of waste/ pollution, instead of dealing with it at the end of the pipe. The innovation processes needed for sustainable development will not take off all by themselves. The competitive environment in which corporations operate requires them to react to market incentives. Market prices are determined by short-term developments. Fluctuations are not connected to the long-term scarcity or abundance of resources but by short-term developments such as storms that destroy oil platforms or local revolutions. ${ }^{1}$

To give companies the scope to innovate also implies that the institutional arrangements of the markets should be changed, i.e., government agencies, tax laws, national laboratories, nongovernmental organizations, etc. should be involved in the process. Moreover, the market mechanism creates a short-term mindset in companies as well as

\footnotetext{
${ }^{1}$ In 1980, economist Julian Simon and Paul Ehrlich (with Holdren the author of the IPAT equation), disputed the scarcity of ores. Simon challenged Ehrlich to put his money where his predictions were (Ehrlich had been predicting massive shortages within a decade, whereas Simon claimed that metal ores were abundant). Simon offered Ehrlich a bet: Ehrlich could pick a quantity of any five metals worth $\$ 1,000$ in 1980 . The winner would receive the difference to the 1990 price, after adjusting for inflation, from the loser. Ehrlich agreed to the bet, and chose copper, chrome, nickel, tin, and tungsten. By 1990, all five metals were below their inflation-adjusted price level in 1980. So, Ehrlich lost the bet and sent Simon a check for $\$ 576.07$.
}

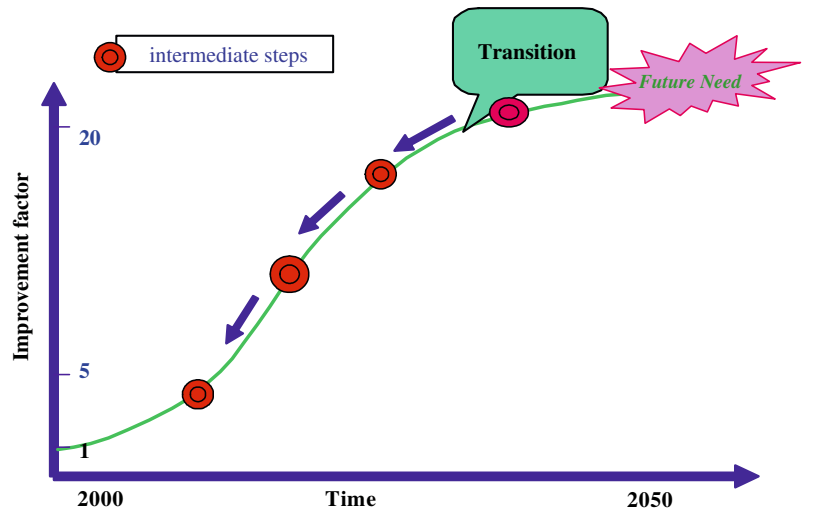

Fig. 4 Backcasting for transitions

among other stakeholders. It is therefore necessary to take an approach to innovation for sustainable development that promotes long-term thinking. As systems innovations and transitions, especially, will be needed, it is important not to start the innovation process by improving current technologies but to start with needs to be fulfilled. These needs should be defined not in technological terms but in basic needs, as reasoning from current technology limits the scope of solutions: "transport" as a requirement easily leads to a clean car, but "access to facilities/work" might bring other options-such as information and communication technology-within reach. This new approach is called backcasting.

\section{Backcasting for transitions}

Optimization of existing technologies is important, but its potential for improvement is often limited. For example, efficiency of electricity production by incineration of fossil fuels (nowadays 40-60\%) cannot be improved more than twofold, as the energy that is present in the chemical bonds of the fuels sets a limit on improvement. If a move to other 
technological systems occurs, the potential might be much larger. However, the needs for which products or services are developed must be addressed in order to achieve improvements.

Backcasting is a methodological approach for sustainable innovations that starts with analyzing needs (Cf. Robinson 1988; Vergragt and van der Wel 1998; Weaver et al. 2000). It aims at generating long-term options for innovations and stakeholder consensus regarding those options. These options cannot be defined very precisely, as new technologies are to a substantial degree unpredictable. They are, so to say, attractive future visions that might be worthwhile to pursue, and therefore they are vehicles to mobilize the required resources. John F. Kennedy's famous 1961 speech in which he stated that the US should "put a man on the moon before the end of this decade" acted as such an attractive future vision. Another example is a recent effort aimed at producing a comparable product to meat (in consumer satisfaction) but based on vegetables (Quist 2007). The backcasting process creates shared visions that could act as guideposts for technological efforts. These visions define broad technological pathways, ${ }^{2}$ not sequential technological steps to be undertaken. Backcasting consists of:

- Analyzing needs

- Identifying options for improvement

- Creating a common future vision with stakeholders

- Developing pathways that could lead to this vision

- Developing consensus on these pathways

\section{Analyzing needs and identifying options}

An important first step in backcasting is the analysis of a need. Before searching for sustainable options to provide for a specific need, various advantages are to be attained by starting analysis at the basic level of the need. Needs might change over time. However, it is unlikely that basic needs will disappear. Basic needs are, for example:

- Food

- Shelter

- Clean air

- Safety

- Clothing

- Water

- Human communication

- Health

- Self-esteem

- Transport

${ }^{2}$ Cf. The Pathways concept of the Alliance for Global Sustainability (MIT, University of Tokyo, Chalmers University, ETH Zurich): http://www.globalsustainability.org/content.cfm?uNav=27\&uLang=1.
To provide for the basic needs, the use of at least the following is necessary:

- Energy

- Materials

- Space

- Education

Therefore, these four elements are added to the list of basic needs.

\section{Identifying options for improvement}

After a first analysis of a need, one could start organizing a brainstorm session to generate options to fulfill the need. Brainstorming should really be focused on needs in order to prevent mere extrapolation of current technology. Options for leapfrogging are required. Some common principles of leapfrogging technologies are to:

- Optimize a system first: only afterward, optimize specific elements of the system, such as products and processes.

- Minimize waste: it not only saves resources, but waste prevention also saves labor and management time.

- Close loops: try to develop technologies in such ways that products at the end of their life can easily be taken apart and re-used/recycled.

- Organize production and consumption in such a way that renewable energy can be used most efficiently.

- Use as little material as possible in the design: the less material, the less need for resource consumption.

- Minimize any damage to ecosystems: prevent using resources that are already consumed in excess of the recovery capacity of planet Earth.

- Introduce flexibility in the technological options: undoubtedly, unforeseen events will occur that will create a need to adapt the innovations being pursued.

\section{Creation of a common future vision}

A common future vision of stakeholders could be a very powerful element to start working toward more sustainable options. Powerful future visions were present in the books of Jules Verne. Science Fiction, as in Star Trek, also contains a powerful future vision. Nanotechnology is often shown as small machines entering your body to detect and attack any virus. Such future visions are often used to legitimize research. They also guide the choices that researchers make. Could a common future vision be reached from the various options for improvement? 
Analyzing from a long-term perspective has a major advantage: if stakeholders are challenged to reason from a long-term perspective, they are less bound to focus at their own direct interests. In discussing long-term goals, actors are less reluctant to acknowledge the legitimacy of each others' interests. Moreover, longer-term interests are less fixed and not strictly defined as yet. Therefore, future visions, or guiding visions, may result from this process.

\section{Developing pathways toward the common future vision}

Consensus on a future vision does not always imply that the stakeholders jointly start to work in the same direction. Actors might very well acknowledge that they should be working in a sustainable direction, but current circumstances drive them in a different direction. To identify promising pathways toward that joint vision, a sociotechnical map might play a role. The sociotechnical map could help identify joint interests and possibilities for compromise. Developing such pathways resembles scenario analysis, a common tool in industrial strategic decision making. In a scenario, a possible future is portrayed. The scenario should be credible and tantalizing as a possible development and should therefore be consistent and sufficiently detailed. For scenario analysis, at least three scenarios are needed. The most important goal of scenarios is not to predict, but to "wake people up" and make them aware of possible changes. Scenarios are often the input for a creative workshop.

Backcasting differs from scenario analysis in the respect that ordinary scenarios are coherent forecasts of several paths into the future, whereas backcasting is trying to identify paths that end at a specific situation. In a scenario, it is attempted to plot the choices or key events and to translate the consequences of a choice or event to later choices or events (a choice often involves the elimination of a later possibility).

During stable times, the mental model of a successful decision maker and unfolding reality match ... in times of rapid change and increased complexity, however, the manager's mental model becomes a dangerously mixed bag: rich detail and understanding can coexist with dubious assumptions and illusory projections (Wack 1985).

Trend scenarios show developments that are in line with current ideas. They are also called "surprise-free scenarios" because they do not incorporate any sudden and unexpected events. The scenarios are normally shown as surrounding a most probable scenario (that often represents "business as usual"). Backcasting is in this respect the reverse of scenarios: it analyzes which paths might be able to lead to the future vision and tries to derive crucial decisions that must be taken in order to reach (one of) the right $\operatorname{track}(\mathrm{s})$.

\section{Example: plastics}

What could be options for a sustainable future for plastic materials? Plastics are a class of products that can be said to be unsustainable in several respects:

- They deplete nonrenewable (or, better, very slowly renewing) resources, such as crude oil (formed over millions of years).

- They generate a variety of emissions.

- They create a waste stream of plastic end products.

One could say that the main problem with plastics is that their production rapidly transforms crude oil into litter, nondegradable waste, and $\mathrm{CO}_{2}$. However, plastics are light-weight materials and therefore efficient in use, and they do not corrode. If it were possible to:

- Produce plastics solely from biomass

- Reuse plastics materials and products

- Burn the remaining waste to recuperate its energy content

then a sustainable plastics "cycle" would be possible.

The current plastics cycle is sketched in Fig. 5. Oil is transformed into the plastic product. This plastic product fulfills needs. The main problems emerge by the fact that plastic is only very slowly transformed to its initial state, crude oil (the problem remains the same if plastics could be made from coal or natural gas) (Fig. 6).

For sustainable development, the objective is to fulfill the need by the product and close the loops around the product as narrow as possible to be most efficient. Therefore, durable products and product re-use are preferred.

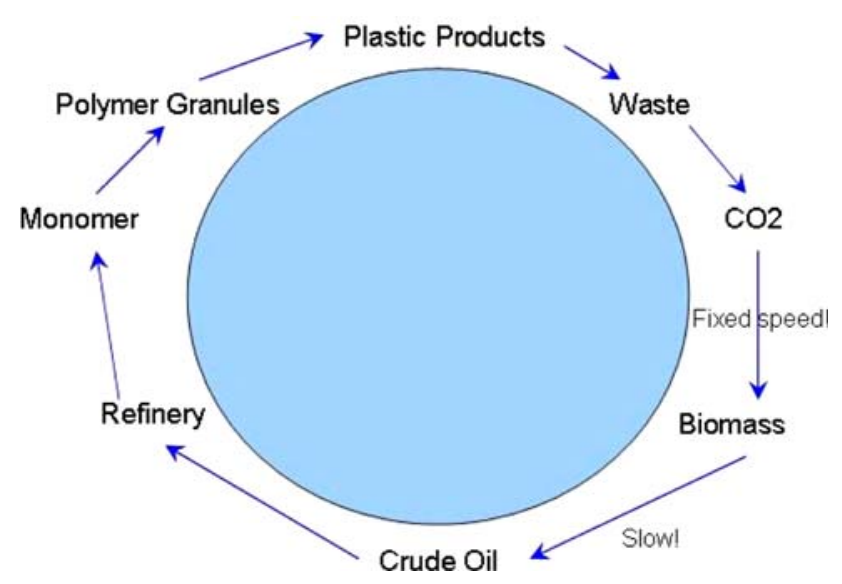

Fig. 5 A sustainable future for plastics? 




Fig. 6 A sustainable future for plastics?

Recycling plastic materials and transforming plastic waste into chemical feedstock contribute to the solution. Using biomass as raw material shortcuts the slowest part of the cycle. Several initiatives have been taken to develop these solutions. Recycling of plastics to feedstock is introduced in some countries, and biomass routes to produce raw materials are studied. These options diminish raw material consumption, which does not have a major economic impact on existing companies. However, if reduction in the consumption of plastics is the target, various interests can be at stake (Mulder 1998, 2006).

\section{Closing remarks}

Technologies can and will have a major role to play in sustainable development but never as the Deus ex machina that will relieve problems at no cost and without requiring any further adaptation. Solutions will always be sociotechnical in nature; they will, in other words, encompass technological as well as social transformation.

Finally, two words of caution are in order here:

- Improved technology may be the enemy of truly sustainable technology. Studies of technological change teach that the development of technology is a pathdependent process, i.e., choices cannot be made freely but are bound by the choices of the past. Similarly, choices today have consequences for the range of options left open to future generations. As a consequence, what today may appear to be an improvement may in fact mean embarking on a technological strategy that prevents the choice of an even better solution later, a phenomenon known as "lock-in".

- Striving only for truly sustainable technologies may stop action being taken now. Solving the problems being faced today will hurt. Doubts about the viability of particular solutions often serve merely as an excuse for postponing action. In practice, the precautionary principle is frequently reversed: as long as the existence and gravity of the problem have not been proven beyond doubt, action is deferred. This is an attitude that can no longer be afforded. To develop new technologies takes time. Even development of a new car, involving no revolutionary new technology, takes about 10 years. Revolutionary changes will take decades of concerted action on the part of governments, consumers, and industry-and particularly the vehicle and energy supply industries.

It is important for society to try and foresee the impact of technological change so that the merits of such change can be discussed democratically. However, experience with parliamentary technology assessment during the last few decades of the twentieth century have shown that no more than limited insight is gained into the future impact of technologies, for that impact is intimately bound up withor even indistinguishable from-wider, more general, cultural changes. Unforeseen rebound effects and new social dilemmas are frequently occurring. They cannot be prevented, and it is therefore crucially important that technological strategies toward sustainability are flexible.

The challenge today is to learn from past mistakes and correct what can be corrected with due haste-and start doing so now.

\section{References}

Abernathy WJ, Clark KB (1985) Innovation: mapping the winds of creative destruction. Res Policy 14:3-22

Bijker WE, Hughes TP, Pinch T (eds) (1987) The social construction of technological systems, new directions in the sociology and history of technology. MIT, Cambridge

Ehrlich PE, Holdren JP (1972) Impact of population growth. In: Ridker RG (ed) Population, resources and the environment. US Government Printing Office, Washington, pp 365-377

Graedel TE, Allenby BR (1995) Industrial ecology. Prentice Hall, Englewood

Hughes T (1983) Networks of power. Electrification in Western society, 1880-1930, Hopkins, Baltimore

Moors E (2000) Metal making in motion, technology choices for sustainable metals production. Delft University Press, Delft

Moors E, Mulder KF (2002) Industry in sustainable development: the contribution of regime change, to adical technical innovation in industry. Int J Technol Policy Manage 2(4):434-454

Mulder KF (1998) Sustainable consumption and production of plastics? Technol Forecast Soc Change 58:105-124

Mulder KF (2006) Sustainable development for engineers-a handbook and resource guide. Greenleaf Publishing, Sheffield

Quist JN (2007) Backcasting for a sustainable future, the impact after 10 years. Eburon, Delft

Rheingold EM (1986) Made in Japan, Akio Morita and Sony. NAL Penguin, New York 
Robinson J (1988) Unlearning and backcasting: rethinking some of the questions we ask, about the future. Technol Forecast Soc Change 33:325-338

Rotmans J, Kemp R, van Asselt MBA (2001) More evolution than revolution: transition management in public policy. Foresight 3:15-32

van de Poel I (2003) The transformation of technological regimes. Res Policy 32:49-68

Vergragt PhJ, van der Wel M (1998) The back-casting approach, sustainable washing as an example. In: Nigel J (ed) Room, sustainable strategies for industry. Island Press
Wack P (1985) Scenarios: uncharted waters ahead. Harvard Business Review 63(5)

Weaver P, Jansen L, van Grootveld G, van Spiegel E, Vergragt PJ (2000) Sustainable technology development. Greenleaf Publishers, Sheffield

Weterings RAPM, Opschoor JB (1992) De Milieugebruiksruimte als uitdaging voor technologie-ontwikkeling. RMNO, Rijswijk 